\title{
A COMPETITIVE IMMUNOSORBENT ASSAY FOR THE DETECTION OF HEAT-STABLE ENTEROTOXIN OF ESCHERICHIA COLI
}

\author{
P. De Mol, W. Hemelhof, P. Retoré, T. Takeda*, T. Miwatani*, Y. \\ TAKEDA $†$ AND J. P. BUTZLER
}

\begin{abstract}
Department of Microbiology, Hopital Universitaire Saint-Pierre, Free University of Brussels, Belgium, *Department of Bacteriology and Serology, Research Institute for Microbial Diseases, Osaka University and $\dagger$ Department of Bacterial Infection, Institute of Medical Science, University of Tokyo, Japan
\end{abstract}

\begin{abstract}
SUmmary. A competitive ELISA procedure for the detection of Escherichia coli heat stable enterotoxin (ST) with monoclonal antibody has been developed. This test is 10 times more sensitive than the suckling-mouse bioassay and it is specific, simple and cheap. A set of 882 strains of $E$. coli isolated from man were tested both by ST-ELISA and suckling-mouse bioassay, the latter serving as the reference method. Positive results in both tests were obtained with 152 strains. The remaining strains gave negative results in both tests, with the exception of two strains, known to be ST producers, that gave negative results in the suckling-mouse assay, but gave positive results by the ELISA method.
\end{abstract}

\section{INTRODUCTION}

Enterotoxigenic strains of Escherichia coli implicated in diarrhoeal disease of man and domestic animals produce a heat-labile enterotoxin (LT) and a heat-stable enterotoxin (ST). Two subgroups of ST have been described (Burgess et al., 1978; Olsson and Soderlind, 1980): STa or STI is methanol-soluble and has biological activity in suckling mice and piglets; and STb or STII, which is methanol-insoluble and has secretory activity only in piglets. The role of STb in pathogenesis has not been established. At least two genetically distinct STa (STI) enterotoxins have been described (Moseley et al., 1980; So and McCarthy, 1980; Moseley et al., 1983): STp is produced by porcine, bovine and human strains and STh is produced only by human strains. STp and STh are also labelled as STIa and STIb respectively. Both STp (STIa) and STh (STIb) have been purified and their amino-acid sequences are known (Aimoto et al., 1982; Takao et al., 1983).

In contrast to the experience with LT, many attempts in the past to raise antibodies against ST in animals by injection of a highly purified form or a crude extract were

Received 10 Sep. 1984; revised version accepted 6 Nov. 1984.

Correspondence should be addressed to P. De Mol, Service de Microbiologie, Hopital Universitaire Saint-Pierre, Rue Haute 322, B-1000, Bruxelles, Belgique. 
unsuccessful (Sack, 1975; Alderete and Robertson, 1978). Only recently, it has been shown that purified ST can be rendered weakly antigenic if coupled to bovine serum albumin (Frantz and Robertson, 1981), or bovine immunoglobulin G (Giannella et al., 1981), or if it is polymerised by treatment with either glutaraldehyde (Van Wynendaele et al., 1982) or toluene-2,4-diisocyanate (Takeda et al., 1981). The availability of ST antibodies enabled several authors to develop either radioimmunoassays (Frantz and Robertson, 1981; Gianella et al., 1982) or enzyme-linked immunosorbent assays (ELISA) (Van Wijnendaele, personal communication; De Mol et al., 1983). These developments encouraged us to produce anti-ST monoclonal antibodies (Hemelhof $e t$ al., 1984). Recently, two other ELISA procedures were described and one of them (Thompson et al., 1984) that made use of monoclonal antibodies was technically similar to the system that we reported previously (De Mol et al., 1983). The other system (Klipstein et al., 1984) is based on a double sandwich technique.

Presently available bioassays for ST, including the suckling-mouse bioassay, are cumbersome and time-consuming but they are the only tests for ST detection used routinely. A simple, rapid immunological assay for ST would facilitate diagnostic work and epidemiological investigations. In this paper we describe and evaluate the ST-ELISA system that we based on our development of a monoclonal anti-STh antibody.

\section{MATERIAL AND METHODS}

Escherichia coli strains. The 882 strains used in this study were from three different sources: (a) 200 strains used in a multilaboratory evaluation by the Diarrhoeal Diseases Control Programme of the World Health Organization were isolated at the Osaka Airport Quarantine Station from patients recently returned from South East Asia with traveller's diarrhoea; they were tested blindly in parallel by ST-ELISA and by the suckling-mouse assay; (b) 237 isolates were collected in Brussels during a routine survey of enterotoxigenic E. coli (ETEC) in liquid stools; (c) 445 isolates were isolated from diarrhoeic and non-diarrhoeic patients in Rwanda, Africa, during an epidemiological study of enteropathogenic agents. Strains were kept on Dorset agar slants at room temperature until used.

Bacterial cultivation. A loopful of stock culture was inoculated into a 100-ml Erlenmeyer flask containing $10 \mathrm{ml}$ of $3 \%$ Trypticase Soy Broth (TSB, bio Mérieux, Marcy l'Etoile 69260 , Charbonnières-les-Bains, France). The strains were grown aerobically for $18 \mathrm{~h}$ at $37^{\circ} \mathrm{C}$ while shaking in a Gallenkamp orbital incubator $(200 \mathrm{rpm})$. After incubation, the cultures were centrifuged at $8000 \mathrm{~g}$ for $20 \mathrm{~min}$, and the supernates were assayed that day or stored at $-20^{\circ} \mathrm{C}$ for no longer than 1 week before testing.

Preparation of STh and monoclonal anti-STh antiserum. STh was purified by reverse-phase high-performance liquid chromatography (Aimoto et al., 1982) and polymerised by glutaraldehyde (Van Wijnendaele et al., 1982). Female Balb/c mice (6 weeks old) received a priming intraperitoneal dose of the polymerised STh (equivalent to $50 \mu \mathrm{g}$ of pure STh) emulsified with complete Freund's adjuvant. After 8 weeks, each mouse received two further doses of $50-\mu \mathrm{g}$ equivalent of polymerised STh intraperitoneally, 3 and 2 days before they were killed. Spleen cells were fused by a modification of the polyethyleneglycol method of Kohler and Milstein (1975) with Sp 2/0 myeloma cells. Anti-STh in culture fluids of fused cells was sought by enzyme-linked immunosorbent assay (ELISA). Specific antibody-producing hybrids were cloned by the limiting-dilution method. Large-scale production of anti-STh was done by intraperitoneal injection of $10^{5}$ hybridoma cells into female Balb/c mice (6 weeks old) after priming with $0.5 \mathrm{ml}$ of Pristane (2,6,10,14-tetramethylpentadecane; Janssen Chimica, Beerse, Belgium). Ascitic fluid was taken 7-10 days after injection of the hybridoma cells. The properties of this antibody preparation will be described elsewhere. It neutralises both STh and STp in the 
suckling-mouse bioassay with a potency about 10 times greater than that of conventionally prepared anti-STh and anti-STp antisera.

$S T$-ELISA procedure. ST was estimated by measuring the extent of inhibition of binding of monoclonal anti-ST antibodies to an excess of solid-phase, fixed, purified STh. The wells of a polystyrene 96-well microtitration plate (Nunc Immunoplate I B.P., 280, Kamstreep, DK-4000 Roskilde, Denmark) were coated overnight at $4^{\circ} \mathrm{C}$ with $100 \mu$ l of carbonate-bicarbonate buffer $(p \mathrm{H} 9 \cdot 6)$ containing purified STh $(2,5 \mu \mathrm{g} / \mathrm{ml})$. The plates were then washed three times with $0 \cdot 1 \mathrm{M}$ phosphate-buffered saline containing $0.01 \mathrm{M}$ sodium phosphate and $0.1 \mathrm{M} \mathrm{NaCl}(\mathrm{PBS} ; p \mathrm{H} 7 \cdot 2$ ) and $0.05 \% \mathrm{v} / \mathrm{v}$ of polyoxyethylene sorbitan monolaurate (Tween 20, U.S. Biochem. Corp., P.O.B. 22400, Cleveland, OH, 44122, USA). Plates were either used immediately or stored at $-20^{\circ} \mathrm{C}$ for up to 1 month. For the test, $50 \mu$ l of test supernate was added to each well (two wells for one test), and immediately thereafter $50 \mu \mathrm{l}$ of monoclonal anti-STh (optimum dilution determined by checkerboard titration) was added. The plates were gently shaken to mix and then incubated for $1 \mathrm{~h}$ at $37^{\circ} \mathrm{C}$. After another washing procedure, $100 \mu$ lof peroxidase-labelled rabbit anti-mouse conjugate (Miles Lab Ltd, POB 37, Stoke Poges, Slough, SL2 4LY) (optimum dilution determined by checkerboard titration) was added to each well and the plates were incubated for $1 \mathrm{~h}$ at $37^{\circ} \mathrm{C}$. After a final washing procedure, $100 \mu \mathrm{l}$ of a substrate solution containing 9 parts of 5 -aminosalicylic and (Sigma) $0.08 \% \mathrm{v} / \mathrm{v}$ in distilled water $(p \mathrm{H} \mathrm{6.0)}$ and 1 part of $\mathrm{H}_{2} \mathrm{O}_{2} 0.05 \% \mathrm{v} / \mathrm{v}$ was added to each of the wells; the plates were incubated at room temperature for $30 \mathrm{~min}$ and thereafter placed at $4^{\circ} \mathrm{C}$ for another $30 \mathrm{~min}$. Optical densities (OD) from clear (positive test) to dark brown (negative test) were read visually by two different technicians and measured with a spectrophotometer (Virion Reader, Institute Virion Ltd, Weingartenstr $9, \mathrm{CH}-8803$ Ruschlikon, Switzerland) at $450 \mathrm{~nm}$. The net OD was calculated by subtracting the OD of the background control wells from that of the corresponding test well. The results were expressed as a percentage of the reading for a negative control (percentage inhibition of the extinction value). Reactions showing an inhibition of $30 \%$ or more of the negative control were considered to be positive.

The ELISA procedure was also performed with conventional antiserum produced in guinea pigs by immunisation with polymerised STh.

Suckling-mouse assay. The suckling-mouse assay was done as previously described (Dean $e t$ al., 1972). Each supernate was tested in three mice. A ratio of gut weight to remaining body weight $(\mathrm{G} / \mathrm{B})$ of $<0.080$ was considered to be a negative result; ratios in the range $0.080-0.095$ were considered to be questionably positive results and performed again; and ratios $>0.095$ were considered to be positive.

\section{RESULTS AND DISCUSSION}

The titration plot for purified $E$. coli STh is presented in fig. 1, which compares the results obtained with the ST-ELISA performed with monoclonal antibody and with guinea-pig antibodies classically produced by immunisation with polymerised STh. The ST-ELISA procedure with monoclonal antibody is more sensitive and the titration shows a very steep slope, indicating good specificity, and a more clear-cut difference between negative and positive tests. Our ST-ELISA procedure with monoclonal antibody detects $c .300 \mathrm{pg}$ of STh/well $(6 \mathrm{ng} / \mathrm{ml}$ in the test sample) when the cut-off point is fixed at $30 \%$ inhibition. Comparatively, in our experience, the suckling-mouse assay becomes positive with a dose of $5 \mathrm{ng}$ of STh in $0.1 \mathrm{ml}(50 \mathrm{ng} / \mathrm{ml})$ and is therefore ten-fold less sensitive than ST-ELISA. We did not encounter loss of ability to bind antibodies to unmodified STh bound to the solid phase, as described by Thompson et al. (1984). Furthermore, in our experience, a blocking step after coating did not increase the sensitivity of the assay. These differences may be related to variations in the quality of the microtitration plates or of the antibody preparations. Reproducibility of the tests is fairly good; the variations in the percentages of 


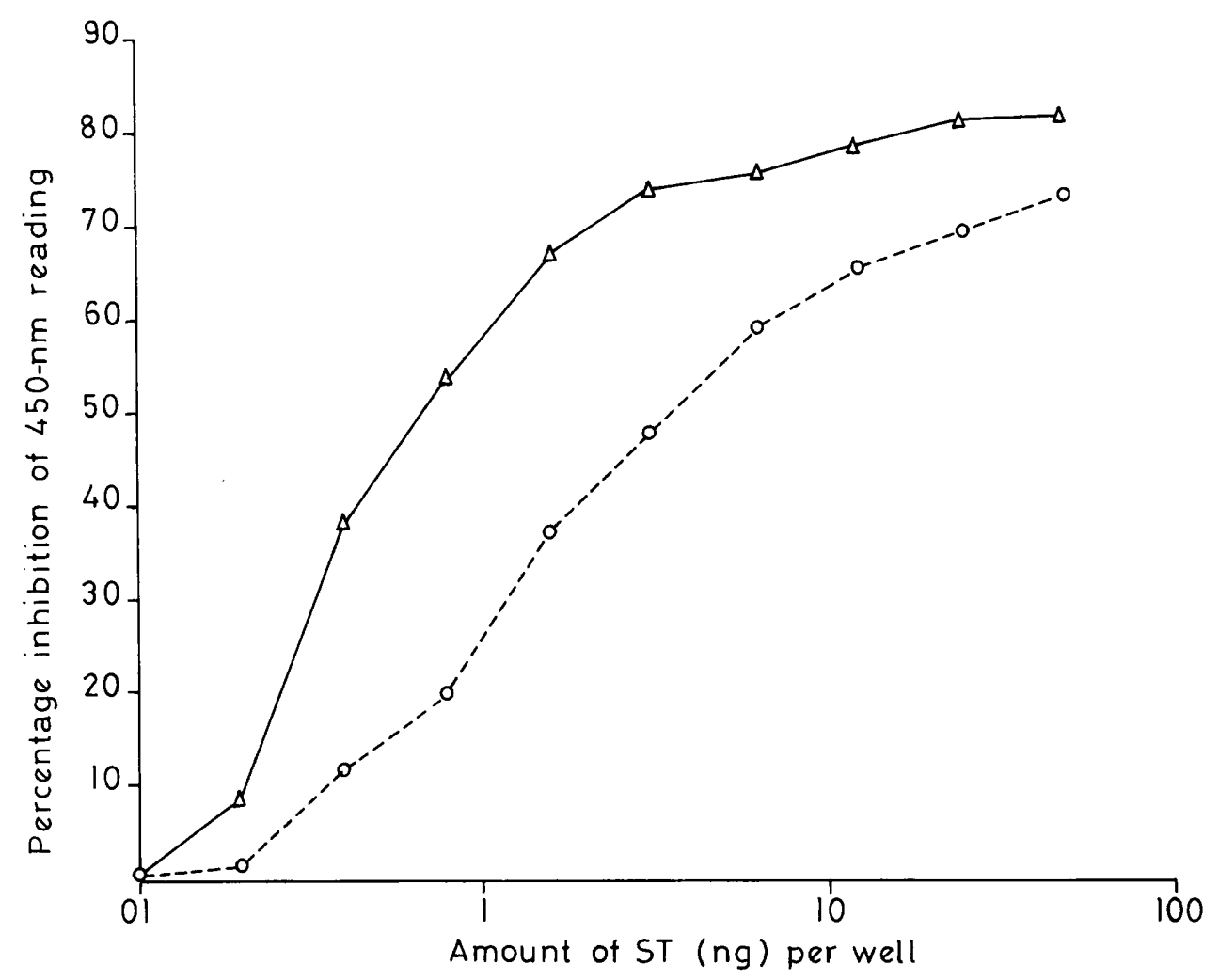

FIG. 1.-Titration curve of purified ST in ST-ELISA tests with two different antibody preparations. ( $\Delta=$ monoclonal antibody; $O=$ conventional guinea-pig antibodies)

inhibition by the same supernate from one day to another was $<10 \%$. One of the 237 Belgian strains and 53 of the 445 Rwanda strains were found to be ST-positive by both techniques. Results of testing reference strains are presented in fig. 2. A discrepancy was observed between the assays for two ST-producing reference strains which gave positive results in our ST-ELISA system and negative results by the suckling-mouse assay (G/B $\leqslant 0 \cdot 075)$. Two further strains, listed as positive, gave negative results by both tests and may, possibly, have lost the relevant Ent plasmid during storage. Linear regression analysis of the results shows a regression coefficient of 0.91 .

The ST-ELISA procedure is very easy to perform and does not require expensive apparatus or materials, with the exception of the need for preparations of purified ST and antibody which are not commercially available; the assay is rapid and can be interpreted in $2.5 \mathrm{~h}$ but, in common with the suckling-mouse and most of the other tests, it requires supernates of agitated $E$. coli cultures that have to be incubated overnight after primary isolation. Large numbers of supernates (184) can be processed on the same day by one technician who does not need special training. The sensitivity and reproducibility of the ST-ELISA system are very good. Visual differences between a negative and a positive test are usually clear. As the monoclonal antibody also effectively neutralises STh and STp, our ELISA procedure would probably detect both toxins and may be of value in the veterinary field. In comparison with bioassay 


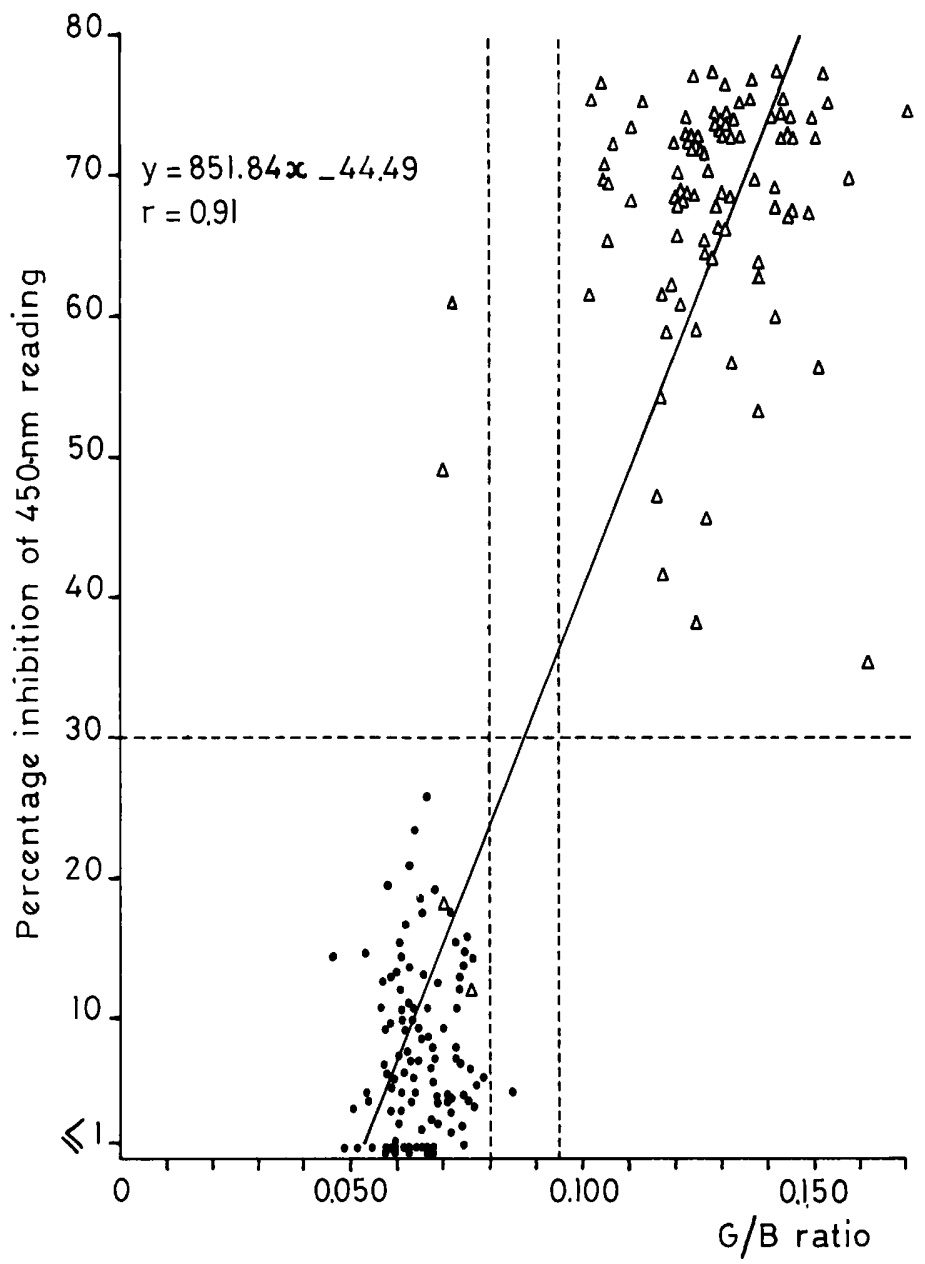

FIG. 2.-Comparisons of results obtained with ST-ELISA (with monoclonal antibodies) and sucklingmouse bioassay in parallel tests with 200 different strains. $(\Delta=$ positive ST; $\bullet=$ negative ST)

procedures, the ST-ELISA offers an easier alternative with greater sensitivity for screening large numbers of strains. It does not require isotopes, as are needed for radioimmunoassay work, and it can be performed in relatively unsophisticated laboratories in field conditions that might be encountered in large epidemiological surveys. We find that it can be performed routinely without problems in our laboratory where it now replaces the cumbersome suckling-mouse assay.

\section{REFERENCES}

Aimoto S, Takao T, Shimonishi Y, Hara S, Takeda T, Takeda Y, Miwatani T 1982 Amino-acid sequence of a heat-stable enterotoxin produced by human enterotoxigenic Escherichia coli. European Journal of Biochemistry 129:257-263.

Alderete J F, Robertson D C 1978 Purification and chemical characterization of the heat-stable enterotoxin produced by porcine strains of enterotoxigenic Escherichia coli. Infection and Immunity 19:1021-1030. 
Burgess M N, Bywater R J, Cowley C M, Mullan N A, Newsome P M 1978 Biological evaluation of a methanol-soluble, heat-stable Escherichia coli enterotoxin in infant mice, pigs, rabbits, and calves. Infection and Immunity 21:526-531.

Dean A G, Ching Y C, Williams R G, Harden L B 1972 Test for Escherichia coli enterotoxin using infant mice: application in a study of diarrhea in children in Honolulu. Journal of Infectious Diseases 125:407-411.

De Mol P, Van Wijnendaele F, Hemelhof W, Corrazza Y 1983 Possible field test for ST-producing Escherichia coli. Lancet 1:524-525.

Frantz J C, Robertson D C 1981 Immunological properties of Escherichia coli heat-stable enterotoxins: development of a radioimmunoassay specific for heat-stable enterotoxins with suckling mouse activity. Infection and Immunity 33:193-198.

Giannella R A, Drake K W, Luttrell M 1981 Development of a radioimmunoassay for Escherichia coli heat-stable enterotoxin: comparison with the suckling mouse bioassay. Infection and Immunity 33:186-192.

Hemelhof W, Retore P, De Mol P, Butzler J P, Takeda T, Miwatani T, Takeda Y 1984 Production of a monoclonal antibody against heat stable enterotoxin produced by human strain of enterotoxigenic Escherichia coli. Lancet 1:1011-1012.

Klipstein F A, Engert R F, Houghten R A, Rowe B 1984 Enzyme-linked immunosorbent assay for Escherichia coli heat-stable enterotoxin. Journal of Clinical Microbiology 19:798-803.

Kohler G, Milstein C 1975 Continuous cultures of fused cells secreting antibody of predefined specificity. Nature 256:495-497.

Moseley S L, Hardy J W, Huq M I, Echeverria P, Falkow S 1983 Isolation and nucleotide sequence determination of a gene encoding a heat-stable enterotoxin of Escherichia coli. Infection and Immunity 39:1167-1174.

Moseley S L, Huq I, Alim A R M A, So M, Samadpour-Motalebi M, Falkow S 1980 Detection of enterotoxigenic Escherichia coli by DNA colony hybridization. Journal of Infectious Diseases 142:892-898.

Olsson E, Soderlind O 1980 Comparison of different assays for definition of heat-stable enterotoxigenicity of Escherichia coli porcine strains. Journal of Clinical Microbiology 11:6-15.

Sack R B 1975. Human diarrheal disease caused by enterotoxigenic Escherichia coli. Annual Review of Microbiology 29:333-353.

So M, McCarthy B J 1980 Nucleotide sequence of the bacterial transposon Tn 1681 encoding a heat-stable (ST) toxin and its identification in enterotoxigenic Escherichia coli strains. Proceedings of the National Academy of Sciences of the USA 77:4011-4015.

Takao T, Hitouji T, Aimoto S, Shimonishi Y, Hara S, Takeda T, Takeda Y, Miwatani T 1983 Amino-acid sequence of a heat-stable enterotoxin isolated from enterotoxigenic Escherichia coli strain 18 D. FEBS Letters 152:1-5.

Takeda T, Takeda Y, Miwatani T, Gregory P, Morita T, Matsushiro A 1981 Genetic labeling of an Ent plasmid that encodes heat-stable enterotoxin of enterotoxigenic Escherichia coli isolated from patients. Biken Journal 24:127-135.

Thompson M R, Brandwein H, Labine-Racke M, Gianella R A 1984 Simple and reliable enzyme linked immunosorbent assay with monoclonal antibodies for detection of Escherichia coli heat-stable enterotoxins. Journal of Clinical Microbiology 20:59-64.

Van Wijnendaele F, Dobrescu L, Boon B 1982 Induction of immunity against Escherichia coli ST enterotoxin Zentralblatt für Veterinärmedizin, Reihe B 29:441-450. 